\title{
Resenha do Livro "O Direito e os Medicamentos - Vigilância sanitária, direito do consumidor e regulamentação das práticas químico-
}

\section{farmacêuticas"}

\author{
Por Angelo C. Pinto
}

livro "O Direito e os Medicamentos - Vigilância sanitária, direito do consumidor e regulamentação das práticas químicofarmacêuticas" organizado pelos professores Vitor Francisco Ferreira e Wilson da Costa Santos da Universidade Federal Fluminense, aborda aspectos relevantes da comercialização e do registro de medicamentos no Brasil.

Com o apoio da Sociedade Interamericana de Vigilância Sanitária (SIVS), da Fundação de Amparo à Pesquisa do Rio de janeiro (FAPERJ) e da Universidade Federal Fluminense (UFF), o livro organizado pelos professores da UFF contou com a colaboração de especialistas das áreas de Direito, Farmácia e Química, do Brasil e de Portugal.

A 1a edição do livro em 2 volumes, o primeiro com seis capítulos e o segundo com sete capítulos, trata, em linguagem simples e direta, de temas como os desafios do registro de nanomedicamentos, o uso de sistemas de liberação controlada de fármacos, as controvérsias envolvidas nas reivindicações de patentes para 0 segundo uso terapêutico de fármacos, a regulamentação de medicamentos pediátricos, os conflitos entre os direitos de propriedade e desenvolvimento tecnológico versus direitos da sociedade em ter acesso mais barato aos medicamentos, a licitação de medicamentos pela modalidade pregão, os direitos patentários e o registro de medicamentos genéricos, e o papel da justiça na facilitação do direito da sociedade aos medicamentos que não são distribuídos pelo sistema único de saúde (SUS).

O 10 capítulo, de autoria do exvice-Reitor da Universidade de Coimbra, Professor José Joaquim Gomes Canotilho, é um verdadeiro passeio pela história do Direito e da Farmácia, esta última tão presente na
Data de publicação na Web: 23 de Julho de 2011 Recebido em 08 de Julho de 2011 Aceito para publicação em 11 de Julho de 2011

literatura portuguesa e brasileira, como na obra de Fernando Pessoa e de Jorge Amado, como mostra o professor Canotilho.

Os organizadores do livro estão de parabéns ao reunirem um seleto grupo de estudiosos que, em linguagem simples e agradável, oferecem aos leitores o tema medicamentos sob diversos ângulos e perspectivas.

Este é um livro que deve estar nas estantes de todos aqueles que se interessam pelas questões ligadas aos medicamentos. Não se pode esquecer que o medicamento é instrumento essencial à correção, preservação, manutenção e promoção da Saúde, e que o acesso a ele representa um importante fator de inclusão social.
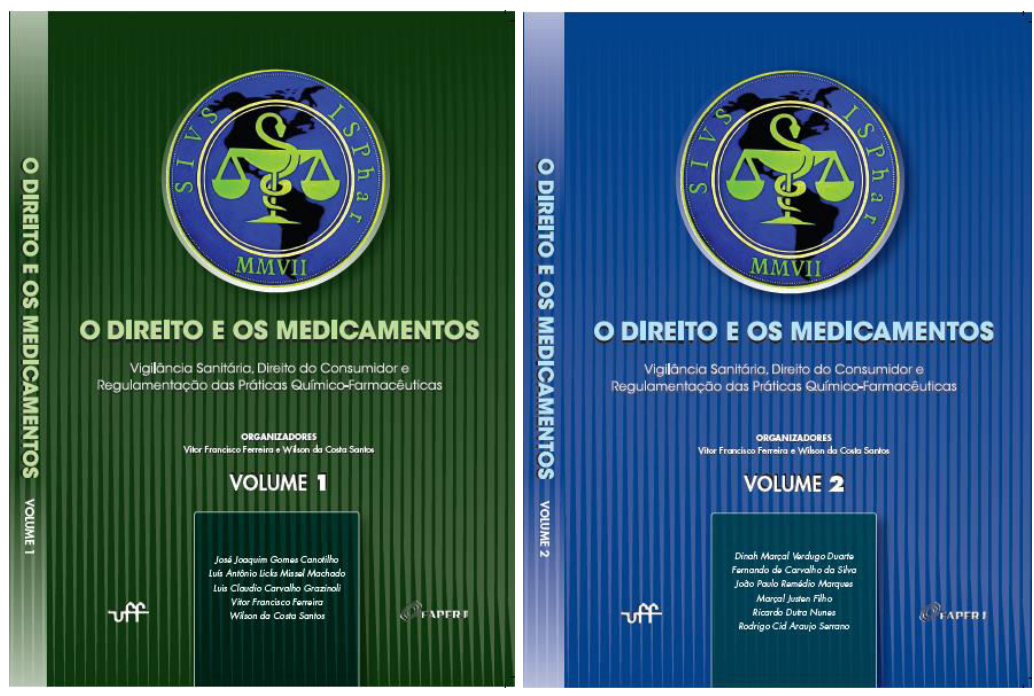

\footnotetext{
* Universidade Federal do Rio de Janeiro, Instituto de Química, Centro de Tecnologia, Bloco A, CEP 21945-990, Cidade Universitária, Rio de Janeiro, Brasil.

Mangelocpinto@gmail.com

DOI: $\underline{10.5935 / 1984-6835.20110029}$
} 